\title{
Gender-specific differences in outcome after trauma may be explained by differences in immunity
}

\author{
Lucas T van Eijk, Matthijs Kox and Peter Pickkers ${ }^{*}$ \\ See related research by Schoeneberg et al. http://ccforum.com/content/17/6/R277
}

With great interest we read the article by Dr Schoeneberg and colleagues regarding gender-specific differences with respect to outcome in patients with severe traumatic injury. The authors show that, apart from the acute phase after trauma, women have a more favorable trauma severity-adjusted outcome, with shorter ICU and hospital stay and lower sepsis rates [1]. However, a possible mechanism of action behind this difference was not suggested. We hypothesize that, in view of the fact that morbidity and mortality in the post-acute phase after trauma are often caused by infectious complications [2], gender differences in immunity might explain the observed differences.

In the general population, women show a lower sepsis incidence compared with men. This difference may be related to a shorter and more pronounced initial innate immune response in females, as we have previously demonstrated during experimental human endotoxemia [3], resulting in more effective bacterial killing [4] and less pronounced immunoparalysis, which is increasingly recognized as the overriding immune dysfunction in sepsis [5]. In turn, this response results in decreased susceptibility towards secondary infections. As sex hormones have been suggested to play a crucial role in the observed gender difference, several trials with estrogens in trauma patients have been completed recently but are not yet published (NCT00973674; NCT00973102).

A better clearance of septic foci and protection against secondary infections may thus account for the shorter ICU stay observed in women. This theory supports the currently prevailing idea that an adequate proinflammatory cytokine response is of benefit, rather than harmful, especially after the initial resuscitation phase of trauma.

\section{Authors' response \\ Carsten Schoeneberg, Max Daniel Kauther, Björn Hussmann, Judith Keitel, Daniel Schmitz and Sven Lendemans}

We are very pleased that our article attracted interest. We would like to thank van Eijk and colleagues for presenting a possible explanation for the finding of lower sepsis rates in women. We are looking forward to results of the trials with estrogens in trauma patients, because different results could be found in the literature. For example, Sperry and colleagues reported that factors other than sex hormones are responsible for the lower sepsis rate in women [6].

In our view, the most interesting result of our research was that women died more frequently soon after trauma compared with men [1]. A possible explanation for this observation might be that women are more vulnerable to hemorrhagic shock. Perhaps this finding is also associated with hormone differences.

* Correspondence: Peter.Pickkers@Radboudumc.nl

Department of Intensive Care Medicine, Radboud University Medical Centre, PO Box $91016500 \mathrm{HB}$, Nijmegen, The Netherlands
We believe more investigation is necessary to understand gender-specific differences. This understanding might result in different strategies in treatment of women and men. Women may need a more aggressive treatment for hemorrhage.

\section{Competing interests}

The authors declare that they have no competing interests.

Published: 17 Mar 2014

\section{References}

1. Schoeneberg C, Kauther MD, Hussmann B, Keitel J, Schmitz D, Lendemans S: Gender-specific differences in severely injured patients between 2002 and 2011: data analysis with matched-pair analysis. Crit Care 2013, 17:R277.

2. Hietbrink F, Koenderman L, Rijkers G, Leenen L: Trauma: the role of the innate immune system. World J Emergency Surg 2006, 1:15. 
3. van Eijk LT, Dorresteijn MJ, Smits P, van der Hoeven JG, Netea MG, Pickkers $P:$ Gender differences in the innate immune response and vascular reactivity following the administration of endotoxin to human volunteers. Crit Care Med 2007, 35:1464-1469.

4. Netea MG, van der Meer JW, van Deuren M, Kullberg BJ: Proinflammatory cytokines and sepsis syndrome: not enough, or too much of a good thing? Trends Immunol 2003, 24:254-258.

5. Leentjens J, Kox M, van der Hoeven JG, Netea MG, Pickkers P: Immunotherapy for the adjunctive treatment of sepsis: from immunosuppression to immunostimulation. Time for a paradigm change? Am J Respir Crit Care Med 2013, 187:1287-1293.

6. Sperry JL, Nathens AB, Frankel HL, Vanek SL, Moore EE, Maier RV, Minei JP, Inflammation and the Host Response to Injury Investigators:

Characterization of the gender dimorphism after injury and hemorrhagic shock: are hormonal differences responsible? Crit Care Med 2008, 36:1838-1845.

$10.1186 /$ cc13768

Cite this article as: Eijk et al:: Gender-specific differences in outcome after trauma may be explained by differences in immunity. Critical Care $2014,18: 418$ 